\title{
Intraventricular conduction defects in acute myocardial infarction
}

\author{
Paolo Rizzon, Matteo Di Biase, and Claude Baissus ${ }^{1}$ \\ From Division of Cardiology, Policlinico, University of Bari, Italy
}

Of 325 consecutive cases with acute myocardial infarction admitted to a coronary care unit, II 3 per cent developed one or more intraventricular conduction defects as an early, and often transient complication. The most common intraventricular conduction defect was block of the anterior fascicle, followed by complete right bundle-branch block, and by the association of right bundle-branch block with anterior fascicular block. Complete left bundle-branch block and the association of right bundle-branch block with block of the posterior fascicle were less frequent. The rarest intraventricular conduction defect was pure posterior fascicular block. The electrocardiographic localization of acute myocardial infarction was most commonly anterior in cases with anterior fascicular block or right bundle-branch block with anterior fascicular block; frequently anterior or anterior and inferior in cases with left bundle-branch block, right bundle-branch block with posterior fascicular block, or posterior fascicular block alone.

Anterior fascicular block did not modify the mortality rate which was increased, but not significantly, by left and by right bundle-branch block. The presence of more than one intraventricular conduction defect was associated with a mortality rate of 47 per cent, a significantly higher figure. The cause of death was mainly shock and/or left ventricular failure. The incidence of high grade or complete AV block was higher in patients with intraventricular conduction defect, but the difference was not statistically significant; the mortality rate in this group was 60 per cent when cases with block of the anterior fascicle were excluded.

Cases with right bundle-branch block and block of the anterior fascicle, and cases with right bundle-branch block and block of the posterior fascicle showed severe two- or three-vessel atherosclerotic coronary artery disease. An infarction involving the anterior two-thirds of the ventricular septum was present in the first group, an infarction of the entire septum or of its middle and posterior thirds in the second group.

On the basis of the clinical, electrocardiographic, and anatomical findings in cases with posterior fascicular block an alternative pathogenetic interpretation of this intraventricular conduction defect is proposed.

Most electrocardiographic and clinical studies of intraventricular conduction defects in acute myocardial infarction deal with selected conduction disturbances (Wanka and Lajos, 1969; Norris and Croxson, 1970; Marriott and Hogan, 1970; Roos and Dunning, 1970; Scanlon, Pryor, and Blount, 1970; Godman, Lassers, and Julian, 1970; Lim, Toh, and Low, 1971; Gould et al., 1972; Norris, Mercer and Croxson, 1972; Bouvrain et al., 1972; Fenig and Lichstein, 1972; Kincaid and Botti, 1972).

Only few reports have been devoted to the study

Received 1o February 1974.

${ }^{1}$ Division of Cardiology, Cliniques Saint Elois, University of Montpellier, France. of the whole spectrum of these disturbances (Col and Weinberg, 1972; Scheinman and Brenman, 1972). Posmortem findings are available only in few of the cases studied (Norris and Croxson, 1970; Scanlon et al., I970; Col and Weinberg, 1972; Scheinman and Brenman, I972; Gould et al., 1972).

The purpose of this report is to review our clinical, electrocardiographic, and anatomical experience with intraventricular conduction defects in acute myocardial infarction.

\section{Patients and methods}

Observations were made on 325 consecutive patients with acute myocardial infarction admitted within 24 hours of the onset of the acute episode to our department over a 22-month period (I September 197I to 3I 
June 1973). All patients were monitored electrocardiographically in the coronary care unit during the first 5 to 7 days after admission.

Twelve-lead electrocardiograms were recorded daily during the whole period in hospital. Additional electrocardiographic strips and 12-lead electrocardiograms were recorded whenever intraventricular or atrioventricular conduction defects or other arrhythmias were thought to be present on the monitor. Electrocardiograms from a 30 sec memory loop were available in all cases.

A diagnosis of acute myocardial infarction was made when at least two of the following criteria were present: I) a history consistent with an acute coronary event; 2) pathological $Q$ waves accompanied by evolving ST-T change; 3) an appropriate increase in serum enzymes (creatine phosphokinase, lactic dehydrogenase, cardiac fraction of the lactic dehydrogenase); when left bundlebranch block was present on the electrocardiogram on admission the patient was only included if these serum enzymes were raised.

Patients with the intraventricular or atrioventricular conduction defects occurring during the terminal phase of infarction, or transiently during or after resuscitation, were not included in the study. Complete left and right bundle-branch block were diagnosed according to the criteria proposed by the New York Heart Association (1964). Blocks of the anterior and posterior fascicle of the left bundle-branch were diagnosed according to the criteria proposed by Rosenbaum et al. (1972) for anterior and posterior hemiblocks. For inclusion in this group the QRS axis deviation had obviously not to be the result of the $Q$ waves of infarction. The diagnosis of incomplete bilateral bundle-branch block was made when there was alternating right and left bundle-branch block, right bundle-branch block with anterior or posterior fascicular block, or both.

\section{Results}

Intraventricular conduction defects were observed in 25 per cent of our cases with acute myocardial infarction: in 15 per cent they were already present on the electrocardiogram recorded on admission; in the remaining Io per cent they developed after admission.

Block of the anterior fascicle alone was found in 41 patients $(13 \%)$ : it was present on admission in 32 patients (10\%), and developed later in $9(3 \%)$. Block of the posterior fascicle alone was found in only one patient, in whom it appeared after admission. Complete left bundle-branch block alone was found in 6 patients $(2 \%)$ : it was present in 4 on admission; and it appeared later in 2 . Right bundlebranch block alone was observed in II patients $(3 \%)$; it was present on admission in 5 , and developed later in $6(2 \%)$.

Right bundle-branch block associated with anterior fascicular block was observed in 14 patients $(4 \%)$ : it was present on admission in 5 , and appeared later in $9(3 \%)$. Since in 3 of these 9 patients block of the anterior fascicle was already present on the electrocardiogram on admission, the combination developed after admission in 6 cases ( $2 \%$ ). Right bundle-branch block associated with posterior fascicular block was found in 4 patients; in 2 of these it occurred after admission. Other types of association were: I) I patient with right bundlebranch block and anterior fascicular block on admission, which later developed into left bundle-branch block with right axis deviation; 2) 2 patients with anterior fascicular block on the first electrocardiogram, who subsequently developed complete left bundle-branch block.

The time of onset and the evolution of the group of intraventricular conduction defects developing after admission are shown in the Figure.

In the group of patients without intraventricular conduction defects a first- and second-degree AV block were observed in 8 per cent and in 6 per cent of patients, respectively. In the group of patients with intraventricular conduction defects first- and second-degree AV block were observed in I5 per cent and 7.5 per cent of cases, respectively. The difference in incidence of first-degree AV block in the two groups was the only one of statistical signicance $(P<0.01)$. High grade or complete AV block appeared in 5 per cent of patients without intraventricular conduction defects and in ro per cent of patients with them. The difference was not statistically significant.

Of the 245 patients without intraventricular conduction defects, 165 had anterior wall infarction, II 8 inferior wall infarction, and 42 infarction of both anterior and inferior walls. In the 32 patients with intraventricular conduction defects developing after admission the localization of the infarction was as follows: I) 9 patients with block of the anterior fascicle alone (anterior in 6, inferior in 2, and both anterior and inferior in 1 ); 2) I patient with block of the posterior fascicle alone (this patient was admitted with inferior wall infarction, but developed posterior fascicular block only after a second acute myocardial infarction which involved the anteroseptal wall); 3) 9 patients with right bundle-branch block (in 6 of these right bundle-branch block was the only post-infarction intraventricular conduction defect; in the other 3 block of the anterior fascicle was present on admission and right bundle-branch block appeared later): anterior in 6 ( $\mathrm{I}$ of these had a history of and electrocardiographic evidence of an old inferior wall infarction), inferior in 2, both anterior and inferior in I ; 4) 2 patients with left bundle-branch alone (anterior in I and both anterior and inferior in I); 5) 9 patients with right bundle-branch block and 


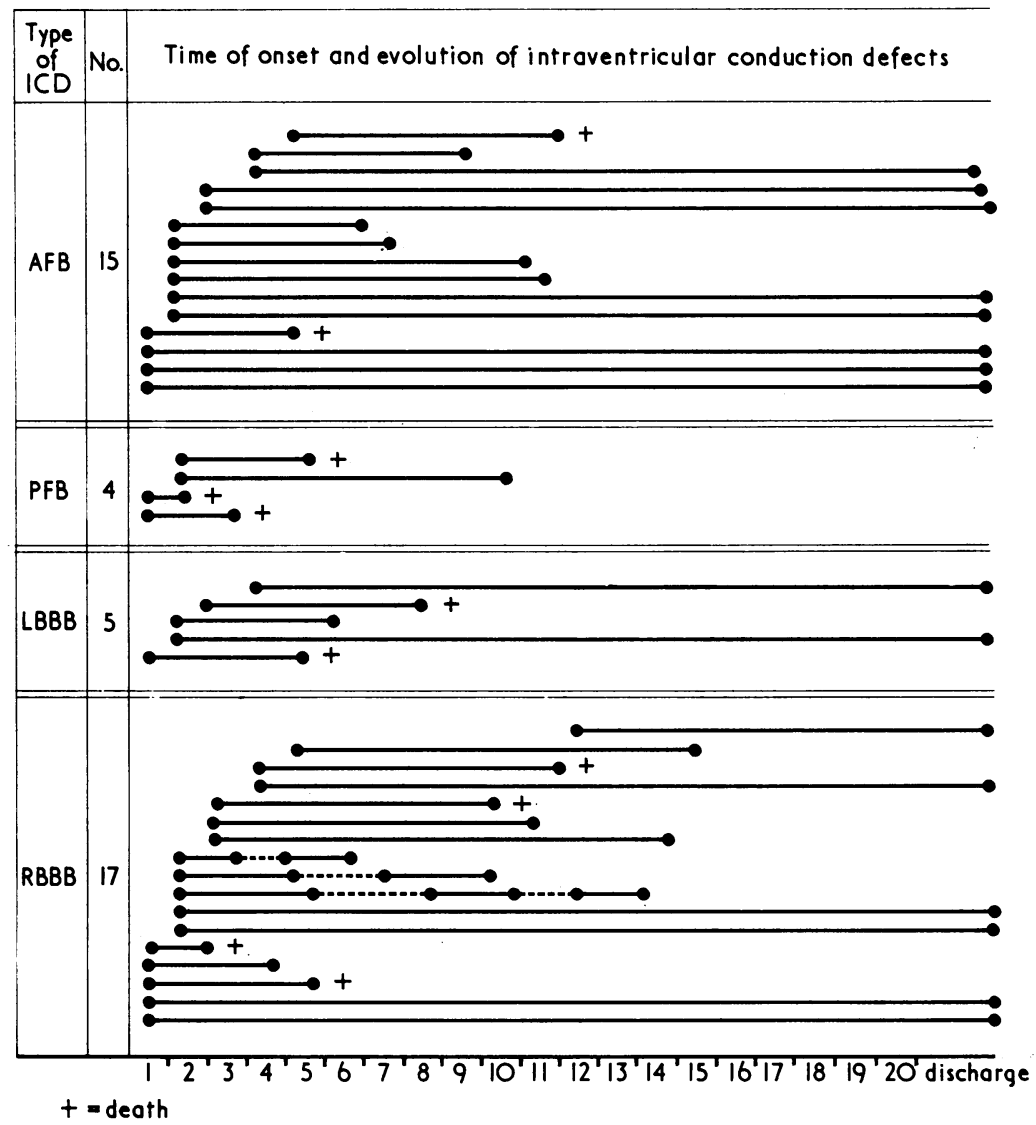

FIG. The time of onset and evolution of intraventricular conduction defects developing after admission to hospital.

anterior fascicular block (anterior in all (2 of them had also history and electrocardiographic evidence of a previous inferior infarction)); 6) 2 patients with right bundle-branch block and block of the posterior fascicle (anterior in both); 7) 2 with block of the anterior fascicle who subsequently developed a left bundle-branch block (anterior and inferior in both); 8) I with right bundle-branch block and block of the anterior fascicle on the admission electrocardiogram, followed by left bundle-branch block with right axis deviation (anterior and inferior).

The mean age of patients without intraventricular conduction defects was 57, that of patients who developed conduction defects after admission was 57, and that of patients with defects on admission was 64 years. The mean age of this last group was significantly higher than that of patients without intraventricular conduction defects $(P<0.01)$.

Of the 245 patients without conduction defects,
I83 were men $(75 \%)$ and 62 were women $(25 \%)$. Of the 80 patients with conduction defects, 57 were men $(71 \%)$ and 23 were women $(29 \%)$.

The mortality rate in the group of patients without intraventricular conduction defects was II per cent, that of patients with conduction defects was 24 per cent. The mortality rate of patients with block of the anterior fascicle alone was 12 per cent, that of patients with right bundle-branch block alone was 18 per cent, that of patients with left bundle-branch block alone was 33 per cent, and that of patients with more than one intraventricular conduction defect was 47 per cent. The mortality rate in this last group was the only one significantly higher than that of patients without conduction defects $(P<0.01)$. The mortality rate in the two principal subgroups - right bundle-branch block with anterior fascicular block, and right bundlebranch block with posterior fascicular block - was 36 per cent and 75 per cent, respectively. Both these 
mortality rates were significantly higher than that of patients without conduction defects.

The cause of death in the 19 patients with intraventricular conduction defects was shock in 7 , shock and left ventricular failure in 5 , left ventricular failure in 2, high grade or complete AV block followed by shock and left ventricular failure in spite of endocardial pacing in 3, recurrent ventricular fibrillation in $\mathrm{I}$, and primary asystole in $\mathrm{I}$.

The mortality rate of high grade or complete AV block was 21 per cent ( 6 out of 28 ) in patients without intraventricular block, and 37 per cent ( 3 out of 8) in those with intraventricular block. If we exclude the 3 patients with block of the anterior fascicle from the last group, mortality rate increases to 60 per cent ( 3 cases out of 5 ).

Necropsy in 4 patients with right bundle-branch block and anterior fascicular block, and in 3 with right bundle-branch block and posterior fascicular block revealed the following cardiac findings:

\section{Right bundle-branch block with anterior fascicular block}

Case I Severe stenosis of the first 3 centimetres of the left anterior descending coronary artery, its first septal penetrating branch, and its diagonal branch; the right coronary artery showed moderate stenosis at the level of its marginal branch and at the crux; recent infarction involving the anterior and the middle thirds of the ventricular septum.

Case 2 Severe stenosis of the upper portion of the left anterior descending coronary artery; severe stenosis of the first centimetre of the left circumflex artery; severe stenosis and occlusion by recent thrombus of the right coronary artery just after its origin; recent infarction involving the anterior and middle thirds of the ventricular septum.

Case 3 Subocclusive stenosis of the middle third of the left anterior descending coronary artery with occlusion by recent thrombosis; moderate stenosis of the first centimetre of the left circumflex artery; multiple moderate stenosis of the right coronary artery and a severe stenosis at the level of its marginal branch; recent infarction of the anterior and middle thirds of the ventricular septum.

Case 4 Severe stenosis with recent thrombosis of the proximal left anterior descending coronary artery; recent transmural infarction of the anterior ventricular wall; transmural infarction of the anterior half of the ventricular septum; subendocardial infarction of the left side of the posterior half of the ventricular septum.

\section{Right bundle-branch block with posterior fascicular block}

Case I Moderate stenosis of the main left coronary artery; diffuse narrowing of the left anterior descending coronary artery which was almost occluded at the level of its middle third; diffuse but moderate stenosis of the left circumflex artery; diffuse stenosis of the right coronary artery, which was severe in the first part and at the beginning of the posterior descending artery; recent infarction of the middle and posterior thirds of the ventricular septum; fibrosis of the superior part of the septum.

Case 2 Severe stenosis of the proximal left anterior descending coronary artery; severe, diffuse stenosis of the right coronary artery; recent large infarction of the inferior wall and recent subendocardial infarction of the ventricular septum extending from the inferior wall almost to the anterior wall.

Case 3 Subocclusive stenosis and recent thrombosis of the main left coronary artery; occlusion of the middle third of the right coronary artery; recent transmural infarction of the middle and anterior third of the ventricular septum, recent subendocardial infarction of the anterior wall; old infarction of the posterior third of the septum and of the adjacent part of the inferior wall.

In all cases the coronary arterial disease was atherosclerotic.

\section{Addendum}

We recently observed another case with acute myocardial infarction and posterior fascicular block. It is mentioned because of its strictly similar behaviour to that of the case included in the present series: a first acute myocardial infarction of the inferior wall with transient second-degree (type I) AV block, followed 20 days later by a second anteroseptal acute myocardial infarction with posterior fascicular block; the patient died of shock. Necropsy showed severe stenosis with recent thrombotic occlusion of the middle segment of the left anterior descending coronary artery, moderate diffuse stenosis of the left circumflex artery and of its marginal branch, diffuse subocclusive stenosis of the right coronary artery with old thrombosis of the posterior descending artery, recent infarction of the anterior and middle thirds of the ventricular septum, and subacute infarction of the inferior wall extending into the posterior third of the septum.

\section{Discussion}

The overall incidence of intraventricular conduction defects in our series of 325 acute myocardial infarction cases is 25 per cent, which compares with a similar figure found by $\mathrm{Col}$ and Weinberg (1972) and with 20 per cent of Scheinman and Brenman (1972). In 15 per cent of cases the intraventricular conduction defect was already present on the electrocardiogram at admission, proving to be permanent until discharge or death in 13 per cent, and transient in the remainder. It is difficult to establish how many cases among the 13 per cent antedated the acute myocardial infarction as an expression of chronic ischaemic heart disease or degenerative disease of the intraventricular conduction system, 
and how many of them were an early consequence of the acute episode preceding hospital admission. It seems reasonable to presume that at least the $\mathrm{I} \cdot 5$ per cent with a transient intraventricular conduction defect were the consequence of the acute myocardial infarction. Adding this $\mathrm{I} \cdot 5$ per cent to the Io per cent of intraventricular conduction defects which developed after admission to hospital, we can assume a rate of II per cent as the minimal incidence of postinfarction intraventricular conduction defects.

The postinfarction conduction defects developed early (mostly within the first 3 days), and lasted only a short time (with an average duration of $5 \frac{1}{2}$ days) in about half of the survivors. The defects that were still present at the end of the hospital stay were probably permanent. This evolution suggests irreversible anatomical damage as a frequent mechanism of intraventricular conduction defects in acute myocardial infarction, in contrast with the almost constantly reversible character of the postinfarction AV block due to involvement of the AV junction.

Anterior fascicular block. Right bundlebranch block alone or in association with anterior and posterior fascicular block

The most common intraventricular conduction defect developing after admission in this series was block of the anterior fascicle alone $(3 \%)$ which compares with 4 per cent of Marriott and Hogan (1970), 4 per cent of Col and Weinberg (1972), and 0.2 per cent of Scheinman and Brenman (1972). The association of anterior fascicular block with right bundle-branch block and right bundle-branch block alone were the second most frequent conduction defects (each $2 \%$ ). Similar figures are given by Marriott and Hogan (1970) (2\%), Scheinman and Brenman (1972) (2\%), and Bouvrain et al. (1972) $(\mathrm{I} \%)$, for the association of anterior fascicular block with right bundle-branch block, and by Scheinman and Brenman (1972) $(2 \%)$ and Bouvrain et al. (1972) (3\%), for right bundle-branch block alone.

The high incidence of these intraventricular conduction defects is easily understandable, since the anterior fascicle of the left bundle-branch and the right bundle-branch, apart from its very initial part, derive their blood supply exclusively from the penetrating branches of the anterior descending coronary artery. In fact, in most of these cases the site of the myocardial infarction was anterior. Similar results are reported in most series: Marriott and Hogan (1970), Roos and Dunning (1970), Norris and Croxson (1970), Godman et al. (1970), Gould et al. (1972), Kincaid and Botti (1972), Scheinman and Brenman (1972), Col and Weinberg (1972). In some cases, however, the site of the acute myocardial infarction was in the inferior wall. Since the blood supply to the anterior fascicle depends only on the anterior wall circulation, it must be assumed that in the case of block of the anterior fascicle alone or with right bundle-branch block, the infarction of the inferior wall is associated with a serious impairment of blood supply to the anterior wall, which presumes pre-existing anterior septal arterial disease. In the case of right bundle-branch block alone, another possible interpretation is suggested by recent anatomical studies, which show that in 20 per cent of normal hearts the initial part of the right bundle-branch receives blood supply only from the AV node artery (Frink and James, 1973). These findings suggest that in some cases an inferior wall infarction (especially if associated with AV block) may be responsible for a proximal type of right bundle-branch block.

The association of postinfarction right bundlebranch block with block of the posterior fascicle was rare in our series $(0.6 \%)$ as in others: 0.4 per cent (Marriott and Hogan, 1970); 0.4 per cent (Scheinman and Brenman, 1972). This association will be discussed when we deal with the posterior fascicular block.

The total incidence of right bundle-branch block developing after admission in our series is thus 5 per cent, which compares with 4 per cent (Bouvrain et al., 1972), 4.5 per cent (Scheinman and Brenman, 1972), and 4 per cent (Norris and Croxson, 1970) in other series.

\section{Left bundle-branch block}

The total incidence of left bundle-branch block developing after admission in our series was much lower ( $1.5 \%$ ), which compares with 0.5 per cent (Norris and Croxson, 1970), I per cent (Bouvrain et al., 1972), 2 per cent (Col and Weinberg, 1972), and 2 per cent (Scheinman and Brenman, 1972) in other series. The lower incidence of left bundlebranch block compared with right bundle-branch block is easily explained, since the main left bundlebranch almost invariably has a double blood supply: an anterior one from the first septal branch of the anterior descending coronary artery and a posterior one from the AV node artery (Frink and James, 1973). Left bundle-branch block is thus expected as a complication only in large infarctions involving most of or the whole ventricular septum, as illustrated by the anatomical findings of Scheinman and Brenman (1972), all five of whose cases had threevessel disease with an infarction involving most of the ventricular septum. 


\section{Posterior fascicular block}

Of all the intraventricular conduction defects, the rarest was block of the posterior fascicle alone $(0.3 \%)$. A similar incidence has been found in other series: 0.2 per cent (Scheinman and Brenman, 1972), 0.4 per cent ( $\mathrm{Col}$ and Weinberg, 1972). The rareness of posterior fascicular block is not easy to explain.

The site of the acute myocardial infarction deserves some consideration. From the study of our patients as well as from a review of published reports, it emerges that anterior or anterior and inferior wall involvement is an almost constant electrocardiographic finding, while exclusively inferior involvement is rare. In the one case of block of the posterior fascicle alone in the present series, as well as in the other observed recently (see addendum), the intraventricular conduction defect developed after an acute myocardial infarction of the anteroseptal wall occurring shortly after an acute myocardial infarction of the inferior wall. The two cases with posterior fascicular block in the series of Wagner and Rosenbaum (1972) had an anterior and an anterolateral infarction. The cases of $\mathrm{Col}$ and Weinberg (1972) and of Slama, Mottè, and Coumel (197I) had anterospetal infarctions. Similar findings were observed with posterior fascicular block associated with right bundle-branch block. The site was anterior in 2 of our 4 cases, and anterior and inferior in the other 2. It was anterior in the case of Roos and Dunning (1970) and in the 2 cases of $\mathrm{Col}$ and Weinberg (1972). The infarction was anterolateral and anterior and inferior in the 2 cases of Marriott and Hogan (1970). It was anterior in 4 cases and inferior in I case in the series of Castellanos et al. (1970). Of the 6 cases of Scanlon et al. (1970) 2 were anterior and inferior, 2 anterior, and 2 inferior.

The site of the infarction is better defined in the few cases studied anatomically. The case with pure posterior fascicular block in the series of Scheinman and Brenman (1972) had infarction of the entire septum, extending into the adjacent anterior and inferior walls. The case we observed recently (see addendum) had three-vessel disease, an acute infarction of the whole ventricular septum, and subacute infarction of the inferior wall. The case of Scanlon et al. (1970), the 2 cases of $\mathrm{Col}$ and Weinberg (1972), and the case of Scheinman and Brenman (1972) with posterior fascicular block and right bundle-branch also showed the presence of a large infarction of the ventricular septum extending into the adjacent anterior and inferior walls. In the case of Roos and Dunning (1970) an extensive anteroseptal infarction was observed. In our 3 cases we observed a severe two- or three-vessel disease, a recent infarction of the whole left side of the ven- tricular septum in 2 cases, and of the posterior and middle thirds of the septum in the third case. In this last case, an old infarction of the upper part of the septum was found as well: an infarction of the inferior wall was present in 2 of these cases, recent in the first and old in the second.

From these data an important conclusion can be drawn: a large infarction involving the entire septum, or most of it, seems necessary to produce posterior fascicular block.

In order to explain the rarity of posterior fascicular block Rosenbaum et al. (1968, I972) stated that the posterior fascicle almost invariably had a double blood supply from the anterior and posterior septal penetrating branches. However, a review of the principal anatomical studies of the circulation of the ventricular septum and of the intraventricular conduction system reveals that there is no direct evidence of a constant dual origin of the blood supply to the posterior fascicle. On the other hand, it has been found that: $I$ ) in many normal human hearts a variable area of the posterior septum (30 to $40 \%$ in $15 \%$ of hearts and 20 to $30 \%$ in $21 \%$ ), which corresponds to the area of distribution of the posterior fascicle, derives its blood supply from branches of the posterior descending artery (James and Burch, 1958); coronary arteriography has also shown that, 'the more cranial and posterior third of the septum receives its blood supply through the short branches derived from the posterior descending artery' (Gensini, Buonanno, and Palacio, 1967); 2) the posterior half of the main left bundle-branch, from which the posterior fascicle arises, is considered to have an entirely posterior blood supply through the AV node artery in 55 per cent of normal human hearts (Frink and James, 1973).

From these data it seems reasonable to assume that in reality both the proximal and distal portions of the posterior fascicle may depend, at least in some cases, on a posterior blood supply. During an acute infarction of the inferior wall which often extends to the posterior part of the septum, the involvement of the posterior fascicle should therefore not be so rare. If we now reconsider the mode of subdivision on the left bundle-branch in the light of the anatomical observations of the majority of pathologists (Mahaim, 193I; Robb, 1965; Barry and Patten, 1965; Sciacca, 1963, 1965; Testoni, 1970; Blondeau and Lenègre, 1970; Demoulin and Kulbertus, 1972, Rossi, 1972), we will find that an early and precise subdivision into two fascicles, anterior and posterior, is unusual; three- or manyfold subdivisions, richly anastomosing with each other, are regarded as a much more common pattern. Recent accurate anatomical studies showed that in more than 50 per cent of hearts in addition to the anterior and 
posterior fascicles a third midseptal fascicle is present (Demoulin and Kulbertus, 1972), and electrophysiological studies showed that ventricular activation in man starts simultaneously in three areas situated in the anterobasal wall, in the mid-septum, and in the junction of the septum with the posterior wall (Durrer et al., 1970). In the remaining cases the left side of the septum is mostly supplied by 'a complicated plexus of ramifications given off by both the anterior and posterior fascicules' and in few cases by ramifications from the posterior fascicle (Demoulin and Kulbertus, 1972).

These anatomical data provide the basis for an alternative interpretation of the main electrocardiographic and anatomical findings in postinfarction posterior fascicular block. Structural or functional damage of the posterior fascicle leading to impaired or blocked conduction is probably not rare during acute myocardial infarction of the inferior wall. However, in the majority of cases (that is when a bifascicular subdivision of the main left bundlebranch is not present), the inferior wall can be activated without delay through the conduction system of the midseptal area and its rich connexions with the Purkinje network of the inferior wall; in order to obtain an electrocardiographic pattern of delayed activation of the inferior wall, coexisting damage of the midseptal fascicle or plexus is necessary. This may be due to acute insufficiency of blood supply from the anterior descending coronary artery when this artery supplies the whole septum, or to a simultaneous insufficiency of both the anterior and posterior wall circulation when the posterior part of the septum is supplied by the posterior circulation; in both cases the result is an extensive septal infarction which accounts also for the frequent involvement of the right bundlebranch. The extremely low incidence of posterior fascicular block alone is explained by the fact that septal damage of this extent is unlikely to spare the anterior fascicle or the right bundle-branch, which are the structures most likely to be affected by ischaemia of the anterior wall. Unless these are spared, the pattern of delayed activation of the inferior wall will be replaced by a post-divisional complete left bundle-branch block or by complete AV block. In fact His bundle electrograms in patients with right bundle-branch block and posterior fascicular block show a widespread impairment of the whole ventricular conduction (Spurrell, Smithen, and Sowton, 1972; Puech and Grolleau, 1972).

\section{Clinical considerations}

An important clinical aspect of intraventricular conduction defects in acute myocardial infarction is their relation to atrioventricular conduction defects, since their relevance to the development of AV block has been emphasized both from the anatomical (Blondeau, Rizzon, and Lenègre, r96I; Sutton and Davies, 1968; Hackel et al., 1972) and electrocardiographic standpoint (Norris, 1969; Norris and Croxson, 1970; Roos and Dunning, 1970; Godman et al., 1970; Lim et al., 1971; Norris et al., 1972; Fenig and Lichstein, 1972; Col and Weinberg, 1972; Scheinman and Brenman, 1972; Bouvrain et al., 1972). Indeed, the incidence of first-degree AV block in our series was significantly higher in the group with intraventricular conduction defects than in the group without. On the other hand, the incidence of second-degree and of high grade or complete AV block was not significantly higher in the group with intraventricular conduction defects. We found no difference in the incidence of complete AV block between patients without intraventricular conduction defects $(5 \cdot 2 \%)$ and patients with block of the anterior fascicle $(7 \cdot 3 \%)$. Patients with right or complete left bundle-branch block had a higher incidence ( $1 \mathrm{I} \cdot 7 \%$ ), but the difference was not statistically significant. Incidences similar to ours are given by some authors: 17 per cent ( $\mathrm{Col}$ and Weinberg, 1972); 12.5 per cent (Scheinman and Brenman, 1972); 13 per cent (Godman et al., 1970); higher figures have been reported by others: I9 per cent (Norris and Croxson, 1970); 27.5 per cent (Bouvrain et al., 1972). The highest incidence of complete heart block was found in patients with the association of two or more intraventricular conduction defects ( $14 \%$ ), but the difference was still statistically not significant when compared with patients without these defects; similar figures are reported by some authors: 18 per cent (Scheinman and Brenman, 1972); 17 per cent (Marriott and Hogan, 1970), while higher figures are reported by Scanlon et al. (1970), 27 per cent; Roos and Dunning (1970), 43 per cent; Bouvrain et al. (1972), 46 per cent; Godman et al. (1970), 7I per cent. The discrepancy between our results and those reported by others may be the result of several factors. We excluded AV block and asystolic arrest occurring as terminal events or transiently after resuscitation, while in most series the inclusion or exclusion of these types of AV block is not specified. Roos and Dunning (1970) included in their series with complete AV block cases with asystole complicating the terminal phase of shock and left ventricular failure. Bouvrain et al. (1972), Fenig and Lichstein (1972), and Godman et al. (1970), included in their cases with incomplete bilateral bundle-branch block those with right or left bundle-branch block associated with first- or second-degree AV block. The clinical importance of the association of intraven- 
tricular conduction defects with a high grade or complete AV block depends on its poor prognosis (mortality rate of $60 \%$ if cases with anterior fascicular block alone are excluded). Our anatomical findings showing, in almost all cases with bilateral bundle-branch block, severe two- or three-vessel disease as well as extensive myocardial infarction, explain the high mortality rate and the frequent failure of endocardial pacing (Norris and Croxson, 1970; Godman et al., 1970; Kostuk and Beanlands, 1970; Lim et al., I97I; Norris et al., 1972; Gould et al., 1972; Scheinman and Brenman, 1972; Bouvrain et al., 1972; Christiansen, Haghfelt, and Amtorp, 1973).

Age did not seem to be an important factor in the development of intraventricular conduction defects after infarction, since the mean age of patients with acute myocardial infarction complicated by conduction defects was the same as that of patients with acute myocardial infarction and normal intraventricular conduction. On the other hand, the average age of patients with acute myocardial infarction who had conduction defects on the electrocardiogram recorded on admission was significantly higher. This observation suggests that this group is probably composed of two subgroups: I) a small number of intraventricular conduction defects which appeared early after acute myocardial infarction and were therefore already present on the electrocardiogram; 2) a large group represented by older patients in whom the conduction defects antedated the acute myocardial infarction, as an expression of a chronic ischaemic heart disease. The results in other series are conflicting: while $\mathrm{Col}$ and Weinberg (1972) found patients with acute myocardial infarction and intraventricular conduction defects to be older than patients without conduction defects, Marriott and Hogan (1970) and Scheinman and Brenman (1972) noted no age difference between the two groups. It must be pointed out that all these studies included all intraventricular conduction defects in the same group, whether or not they were a postinfarction manifestation.

Our observations confirm the findings of others (Marriott and Hogan, 1970; Scheinman and Brenman, 1972; Col and Weinberg, 1972; Kincaid and Botti, 1972) that the prognosis of acute myocardial infarction is not modified by anterior fascicular block. The mortality rate in our patients with acute myocardial infarction associated with right or left bundle-branch block was higher than in those with normal intraventricular conduction, but the difference was not statistically significant. The mortality rate in this group has been found to be higher in other series (Norris and Croxson, 1970; Godman et al., 1970; Col and Weinberg, 1972; Bouvrain et al., 1972), but it is worth noting that the figure nearest to ours is reported by Scheinman and Brenman (1972), the only authors who explicitly excluded those intraventricular conduction defects appearing in the terminal phase. The coexistence of more than one intraventricular conduction defect carried a bad prognosis, i.e. almost a 50 per cent mortality rate, a difference which is statistically highly significant. Other series reported similar or higher figures (Norris and Croxson, 1970; Roos and Dunning, 1970; Scanlon et al., 1970; Marriott and Hogan, 1970; Norris et al., 1972; Gould et al., 1972; Col and Weinberg, 1972; Scheinman and Brenman, 1972). To explain the higher mortality rate in some of these studies, we must remember that, with the exception of Scheinman and Brenman (1972), none of these authors mentioned the exclusion or inclusion of terminal intraventricular conduction defects. The cause of death in patients with conduction defects was shock and/or cardiac failure in the vast majority of cases. Only in a few cases could the associated high grade or complete AV block not be excluded as a factor contributing to the death of the patient. Moreover, the fact that clinical deterioration was not prevented by endocardial pacing seems to support the view that AV block and shock are both expressions of extensive myocardial damage rather than interdependent events.

\section{References}

Barry, A., and Patten, B. M. (1968). The structure of the adult heart. In Pathology of the Heart and Blood Vessels, 3rd ed., p. 123. Ed. by S. E. Gould. Thomas, Springfield, Illinois.

Blondeau, M., and Lenègre, J. (1970). Bloc Atypique de la Branche Droite. Masson, Paris.

Blondeau, M., Rizzon, P., and Lenègre, J. (I96I). Les troubles de la conduction auriculo-ventriculaire dans l'infarctus myocardique récent. Il Etude anatomique. Archives des Maladies du Coeur et des Vaisseaux, 54, I I04.

Bouvrain, Y., Bouchet, P. F., Motte, G., and Roche, P. (1972). Les blocs de branche de la phase aigüe de l'infarctus du myocarde. Archives des Maladies du Coeur et des Vaisseaux, $65,649$.

Castellanos, A., Jr., Maytin, O., Arcebal, A. G., and Lemberg, L. (1970). Significance of complete right bundle-branch block with right axis deviation in absence of right ventricular hypertrophy. British Heart fournal, 32, 85.

Cristiansen, I., Haghfelt, T., and Amtorp, O. (1973). Complete heart block in acute myocardial infarction: drug therapy. American Heart fournal, 85, 162.

Col, J. J., and Weinberg, S. L. (1972). The incidence and mortality of intraventricular conduction defects in acute myocardial infarction. American fournal of Cardiology, 29, 344 .

Demoulin, J. C., and Kulbertus, H. E. (1972). Histopathological examination of concept of left hemiblock. British Heart fournal, 34, 807.

Durrer, D., van Dam, R.Th., Freud, G. E., Janse, M. J., Meijler, F. L., and Arzbaecher, R. C. (1970). Total excitation of the isolated human heart. Circulation, 4I, 899. 
Fenig, S., and Lichstein, E. (1972). Incomplete bilateral bundle-branch block and A-V block complicating acute anterior wall myocardial infarction. American Heart fournal, 84, 38.

Frink, R. J., and James, T. N. (1973). Normal blood supply to the human His bundle and proximal bundle branches. Circulation, 47, 8.

Gensini, G. G., Buonanno, C., and Palacio, A. (1967). Anatomy of the coronary circulation in living man. Coronary arteriography. Diseases of the Chest, 52, 125.

Godman, M. J., Lassers, B. W., and Julian, D. G. (1970). Complete bundle-branch block complicating acute myocardial infarction. New England fournal of Medicine, 282, 237.

Gould, L., Venkataraman, K., Mohammad, N., and Gomprecht, R. F. (1972). Prognosis of right bundle-branch block in acute myocardial infarction. Fournal of the American Medical Association, 219, 502.

Hackel, D. B., Wagner, G., Ratliff, N. B., Cies, A., and Estes, E. H., Jr. (1972). Anatomic studies of the cardiac conducting system in acute myocardial infarction. American Heart fournal, 83, 77.

James, T. N., and Burch, G. E. (1958). Blood supply of the human interventricular septum. Circulation, 17, 391.

Kincaid, D. T., and Botti, R. E. (1972). Significance of isolated left anterior hemiblock and left axis deviation during acute myocardial infarction. American fournal of Cardiology, 30, 797.

Kostuk, W. J., and Beanlands, D. S. (1970). Complete heart block associated with acute myocardial infarction. American fournal of Cardiology, 26, 380.

Lim, C. H., Toh, C. C. S., and Low, L. P. (1971). Atrioventricular and associated intraventricular conduction disturbances in acute myocardial infarction. British Heart fournal, 33, 947 .

Mahaim, I. (193I). Les Maladies Organiques du Faisceau de His-Tawara. Masson, Paris.

Marriott, H. J. L., and Hogan, P. (1970). Hemiblock in acute myocardial infarction. Diseases of the Chest, 58, 342.

New York Heart Association, Criteria Committee (1964). Diseases of the Heart and Blood Vessels. Nomenclature and Criteria for Diagnosis, 6th ed., p. 421. Little Brown, Boston; Churchill, London.

Norris, R. M. (1969). Heart block in posterior and anterior myocardial infarction. British Heart fournal, 31, 352.

Norris, R. M., and Croxson, M. S. (1970). Bundle branchblock in acute myocardial infarction. American Heart fournal, 79, 728.

Norris, R. M., Mercer, C. J., and Croxson, M. S. (1972). Conduction disturbances due to antero-septal myocardial infarction and their treatment by endocardial pacing. American Heart fournal, 84, 560 .
Puech, P., and Grolleau, R. (1972). L'activité du Faisceau de His Normale et Pathologique, p. 139. Ed. by Sandoz. Masson, Paris.

Robb, J. S. (I965). Comparative Basic Cardiology, p. 392 Grune and Stratton, New York.

Roos, J. C., and Dunning, A. J. (1970). Right bundle-branch block and left axis deviation in acute myocardial infarction. British Heart fournal, 32, 847.

Rosenbaum, M. B., Elizari, M. V., and Lazzari, J. O. (1968) Los Hemibliqueos. Paidos, Buenos Aires.

Rosenbaum, M. B., Elizari, M. V., Lazzari, J. O., Kretz, A., and Da Ruos, H. O. (I972). The clinical causes and mechanism of intraventricular conduction disturbances. In Advance in Electrocardiography, p. 183. Ed. by R. C. Schlant and J. W. Hurst. Grune and Stratton, New York.

Rossi, L. (1972). Histopathology of the conducting system. Giornale Italiano di Cardiologia, 2, 484.

Scanlon, P. J., Pryor, R., and Blount, S. G. (1970). Right bundle-branch block associated with left superior or inferior intraventricular block. Circulation, 42, I 135.

Scheinman, M., and Brenman, B. (1972). Clinical and anatomic implications of intraventricular conduction blocks in acute myocardial infarction. Circulation, 46, 753.

Sciacca, A. (1963). Studio morfologico della disposizione e della variazione quantitative del tessuto specifico in seno al tronco comune del fascio di Paladino-His. Archivio Italiano di Anatomia e di Embriologia, 58, 162.

Sciacca, A. (1965). Le basi anatomiche dei blocchi atrioventricolari. In Atti $X X V$ Congresso Società Italiana di Cardiologia, Roma, Vol. $2^{\circ}$, p. 126. Italian Society of Cardiology, Rome.

Slama, R., Mottè, G., and Coumel, P. (1971). Les Blocs Auriculo-Ventriculaires. Bailliere, Paris.

Spurrell, R. A. J., Smithen, C. S., and Sowton, E. (1972). Study of right bundle-branch block in association with either left anterior hemiblock or left posterior hemiblock using His bundle electrograms. British Heart fournal, 34, 800.

Sutton, R., and Davies, M. (1968). The conduction system in acute myocardial infarction complicated by heart block. Circulation, 38, 987.

Testoni, F. (1970). Aspetti elettrocardiografici dei blocchi intraventricolari. Editoriale. Progresso Medico, 26, 537.

Wagner, R., and Rosenbaum, M. B. (1972). Transient left posterior hemiblock. Association with acute lateral myocardial infarction. American fournal of Cardiology, 29, 558.

Wanka, J., and Lajos, T. Z. (1969). Prognosis of right bundlebranch block with left axis deviation (abstract). Circulation, 39 and 40, Suppl. III, 212.

Requests for reprints to Professor P. Rizzon, Divisione di Cardiologia, Clinica Medica $\mathrm{I}^{\circ}$, Universita, 70100 Bari, Italy. 